\title{
A criação de uma marca-lugar a partir dos enunciados políticos: as cidades como organizações discursivas
}

The creation of a place branding from political statements: cities as discursive organizations

La creación de una marca lugar a partir de declaraciones políticas: las ciudades como organizaciones discursivas

Rodrigo Maurício Freire Soares

- Professor do curso de Relações Públicas da Universidade do Estado da Bahia (Uneb).

- Doutorando do Programa de Pós-Graduação em Comunicação e Cultura Contemporâneas da Universidade Federal da Bahia (UFBA).

- Pesquisador do Grupo de Estudos de Comunicação, Política e Redes Digitais (CP-Redes) da UFBA.

- Mestre em Desenvolvimento e Gestão Social pela UFBA.

- Graduado em Comunicação Social - Relações Públicas pela Uneb.

- E-mail: rmsoares@uneb.br 


\section{Resumo}

Este artigo tem como objetivo discutir a relação entre o discurso político e os aspectos simbólicos que integram a ideia de marca-lugar. A fundamentação teórica considera perspectivas de discurso, marca cidade e marca. Os resultados indicam que o discurso político é parte integrante da visão de cidade, estabelecendo-se como um elemento do contrato de comunicação entre os governantes e a população.

PALAVRAS-CHAVE: MARCA-LUGAR・DISCURSO POLÍTICO・CIDADES.

\section{Abstract}

This article aims to discuss the association between political discourse and the symbolic aspects that integrate the idea of place branding from the perspectives of discourse, city branding, and brand (Semprini, 2006). The results indicate that the political discourse is a key component of city vision, comprising an element of the government-population communication contract.

KEYWORDS: PLACE BRANDING • POLITICAL SPEECH・CITIES

\section{Resumen}

Este artículo tiene como objetivo discutir la relación entre el discurso político y los aspectos simbólicos que integran la idea de marca lugar. El marco teórico utilizado considera la perspectiva discursiva, la marca ciudad y la marca. Los resultados indican que el discurso político es parte integral de una visión de ciudad, constituyéndose como un elemento del contrato de comunicación entre el gobierno y la población. 


\section{INTRODUÇÃO}

Todas as vilas e povoações de engenhos desta costa, fiz cercar de taipa, com os seus baluartes, e as que estavam arredadas do mar, fiz chegar ao mar, e lhes dei toda a artilharia que me pareceu necessária, a qual está entregue aos vossos almoxarifes [...] mandei em todas as vilas fazer casas de audiência e de prisão, e endireitar algumas ruas, o que tudo se fez sem opressão do povo.

(Carta de Tomé de Sousa, 1 de junho de 1553)

0 s relatos de Tomé de Sousa a Dom João III sobre as suas ações após a fundação de Salvador trazem uma visão estratégica da cidade naquele período histórico. Como uma das primeiras cidades planejadas no período do Renascimento, Salvador constituía-se como um território de defesa contra a ação de piratas e invasores de outras nações, sendo um dos maiores empreendimentos da América Lusitana no século XVI e uma das cidades mais bem fortificadas do mundo à época. Deste marco zero até os dias atuais, a noção de cidade sofreu profundas alterações. A cidade tratada pela administração local do Brasil colônia como um sítio de defesa tornou-se gradativamente aberta ao externo, às trocas e ao diálogo intercultural, culminando, mais recentemente, em sua inserção como uma metrópole global.

Este processo acirra-se na contemporaneidade como sintoma de um mundo cada vez mais conectado e interdependente. Os sentidos atribuídos aos lugares passam a posicionar as cidades em uma perspectiva global. Como afirmou Milton Santos (1996, p.273), "cada lugar é, ao mesmo tempo, objeto de uma razão global e de uma razão local, convivendo dialeticamente". Neste contexto globalizado, ganham força outros atributos das cidades, sobretudo os seus significados simbólicos construídos culturalmente, através de narrativas pessoais vividas e historicamente enraizadas. De forma complementar, a sociedade informacional contemporânea nos incita a compreender as novas territorialidades que decorrem de uma relação entre a comunicação (meios) e o poder público (Estado).

Em um contexto de constante virtualização das instituições sociais, as ações do ente governamental passam por transformações, seja pela sua "domesticação" - acesso a serviços públicos por meio de um computador em casa -, seja pela sua inserção em contextos de disputas de narrativas simbólicas - as realizações da administração pública cada vez mais influenciadas pelos símbolos e conteúdos midiáticos. Há, no âmbito da comunicação pública, um processo de desterritorialização da experiência e da interação social:

[...] a sociedade contemporânea (dita 'pós-industrial') rege-se pela midiatização, quer dizer, pela tendência à 'virtualização' ou telerrealização das relações humanas, presente na articulação do múltiplo funcionamento institucional e de determinadas pautas individuais de conduta com as tecnologias da comunicação. (Sodré, 2002, p.21)

As marcas de uma gestão entrelaçam-se com o espaço público como realizações de uma administração, como promoções de si mesmas inseridas em uma ambiência concorrencial que caracteriza o universo imagético das marcas, sendo as obras, os projetos e os programas os seus próprios elementos de distinção. Nesse sentido, o objetivo deste artigo é discutir como se dá a relação que se estabelece entre a esfera política em seu campo discursivo e os aspectos simbólicos que conformam as noções de criação de marcas para os lugares. As discussões aqui apresentadas buscam, portanto, compreender o processo de criação de uma marca-lugar, tendo como enfoque o papel da administração pública. Trataremos dos principais conceitos que envolvem a ideia de marca-lugar a partir das contribuições de Lynch (1960) e Kavaratzis e Ashworth (2006) de forma a circunscrever o fenômeno em um campo conceitual. 
Será discutida a percepção da administração pública municipal de Salvador, buscando evidenciar a estratégia discursiva idealizada em um ciclo de gestão mais recente, cujos aspectos metodológicos se apoiarão nas concepções de análise de discurso de Charaudeau (1999, 2006b, 2016). O recorte para análise centra-se no discurso de posse do prefeito eleito Antônio Carlos Magalhães Neto, que governou a cidade no período de 2013 a 2016, buscando identificar a sua concepção inicial para a cidade, antes do início efetivo de sua administração. Que ideia de cidade se projetava? 0 que fora evocado em seu discurso? Ao final, serão comparadas as categorias de discurso presentes e como tais elementos conformam uma ideia de marca-lugar.

\section{A CONSTRUÇÃO DA MARCA NA PÓS-MODERNIDADE E NOÇÕES SOBRE MARCA-LUGAR}

Ao tratar de Londres e Paris, Lynch (1960) já chamava atenção para a necessidade de que as cidades fossem "legíveis", ou seja, que cada parte da cidade pudesse ser compreendida dentro de um padrão de coerência. De forma complementar, o autor abordou também a questão da "imageabilidade", cuja definição refere-se às condições para que o interlocutor pudesse interpretá-la, que fosse possível conformar uma imagem de uma dada localidade. Este viés trazido pelo autor ancora-se prioritariamente em aspectos urbanísticos e de arquitetura, em uma dimensão da infraestrutura, que é objeto recorrente das administrações municipais. No campo do tangível, ruas, praças e vias conferem este atributo de "imageabilidade", cabendo ao papel do poder público conferir estes sentidos.

A construção de uma marca para as cidades vai além da dimensão unicamente turística e de investimentos em infraestrutura, uma vez que opera em um campo de disputas pela atração de empresas, serviços e retenção de mão de obra qualificada. Os lugares se constituem em fenômenos passíveis de branding, com aplicação de práticas comunicacionais que têm como objetivo diferenciar cidades, regiões e países em um mercado concorrencial (Kavaratzis; Ashworth, 2006).

0 processo de criação de marcas, na concepção de Semprini (2006), deve considerar as suas dimensões semiótica, relacional, contratual e evolutiva. As marcas são dotadas de uma dimensão semiótica, pois veiculam significado ao longo do tempo, ao passo que devem ser relacionais, pois são resultado de trocas e de negociações de sentido entre distintos interlocutores. Transpondo essa abordagem para o campo das cidades, a criação da marca-lugar de um destino dependerá de sentidos e significados construídos ou evocados, os quais serão consolidados por meio de estratégias de comunicação que envolvem diferentes atores.

A construção da marca de uma cidade é derivada de uma ação dialógica entre os diversos públicos responsáveis pela sua concepção, devendo ser capaz de evidenciar os aspectos culturais locais, sob o risco de a marca tornar-se uma replicação padronizada de discursos/narrativas observáveis em outros lugares. Em uma dimensão contratual, a marca de uma cidade é uma promessa que solicita do interlocutor o seu reconhecimento.

Charaudeau (2006a), ao definir os atributos do discurso político, chama atenção para a relação entre a linguagem e a ação, entre o dizer e o fazer, que buscam aproximar o ideal da política de sua prática, perfazendo um contrato de comunicação entre os atores políticos e a opinião pública. Os governantes buscam, por meio da palavra, persuadir a audiência sobre a sua visão de gestão:

Para o político, é uma questão de estratégia a ser adotada na construção de sua imagem (ethos) para fins de credibilidade e sedução, da dramatização do ato de tomar a palavra (pathos) para fins de persuasão, da escolha e da apresentação dos valores para fins de fundamento do projeto político. (Charaudeau, 2006a, p.84) 
A criação de uma marca para uma cidade é a representação de um projeto político, estando sujeita a todas as encenações e nuances de verdade do discurso. A concepção de uma cidade inclui, contudo, uma visão ampla que abrange os cidadãosmoradores, as projeções de agências de branding e esta dimensão política discursiva dos governos. Os diferentes agentes envolvidos nesta construção têm agendas políticas diferentes, podendo resultar em objetivos e motivações igualmente distintas. Semprini (2006), ao tratar dos polos - produção, recepção e contexto geral - já nos sinalizava acerca dessa dimensão intersubjetiva que integra o composto da marca. Contudo, interessa-nos aqui o polo de produção, especificamente o papel da administração municipal neste processo. A construção de uma marca cidade é resultado de etapas gradativas e sucessivas. Há, contudo, um momento inicial em que essa estratégia de construção tem início. Uma vez eleitos, os gestores públicos municipais, em seus discursos de posse, apresentam suas concepções da cidade, bem como suas perspectivas de futuro.

\section{O DISCURSO POLÍTICO: ENUNCIANDO UMA VISÃO PARA A CIDADE}

O discurso político está fundamentado em um contrato de comunicação que transita nos campos da governança, da opinião e da mediação. Charaudeau (2006a) ressalta que o discurso político é dotado de alguns princípios, quais sejam: 1) alteridade - a existência de si depende do outro; 2) influência - a tentativa de trazer o outro para o seu universo discursivo; 3) regulação - admissão de que o outro tem o seu projeto de influência, sendo necessário regulá-lo; e 4) pertinência - admissão de que 0 ato de linguagem só é possível a partir de elementos partilhados. 0 discurso político situa-se em um campo de tensão que busca regular o consentimento da audiência, a qual é colocada diante de fatos que trazem uma "força de verdade", um imaginário de verdade inerente ao contrato de comunicação. Como afirma o autor:

[...] os políticos, nesse mundo moderno da encenação e do espetáculo, se quiserem exercer alguma influência sobre os cidadãos, devem aprender as novas regras de insinceridade e do mentir verdadeiro legítimos, aceitar esse paradoxo moderno segundo o qual se dá uma grande importância ao parecer justamente numa época em que a cidadania é mais esclarecida. (Charaudeau, 2006a, p.305-306)

Ainda que o discurso político seja marcado por este aspecto de teatralização e sedução que permeia a relação entre cidadãos, mídia e governantes, deve-se considerar nos discursos dos gestores uma concepção implícita de cidade. Há um convencimento, e isso parece evidente na obra de Charaudeau como parte do ethos político, que passa por persuadir o cidadão sob uma determinada perspectiva. Se observarmos os discursos de posse dos prefeitos eleitos dos municípios, visualizaremos uma perspectiva de cidade. Estes discursos se dão, sobretudo, observando sua provável repercussão, estando presente uma preocupação adicional com os desdobramentos possíveis a partir da sua midiatização. Segundo Hjarvard (2008), o processo de midiatização nos mostra como a lógica da mídia passa a exercer influência em diversos outros campos de análise (religião, educação etc.), sendo muito evidente no campo da política. Por midiatização da política entendemos o processo pelo qual a política gradualmente se torna dependente das instâncias midiáticas e de suas lógicas. Como resultado deste processo, tem-se a consolidação da mídia como lugar decisivo para a formação da opinião pública.

Neste escopo, podemos afirmar que profissionais de relações públicas estão em uma posição estratégica para orientar a comunicação de organizações e governos, promovendo diálogos e fluxos de informação junto a distintos públicos - a função política das Relações Públicas (Simões, 1995, 2001). Sobre essa dimensão política, Strömbäck e Kiousis (2011) complementam:

As relações públicas na política são o processo de gestão através do qual uma organização ou ator individual para fins políticos, através de ação comunicativa intencional, procura influenciar e estabelecer, construir e manter relações benéficas e a sua reputação com os seus públicos-chave para ajudar a suportar a sua missão e atingir os seus objetivos. (p.8) 
0 consentimento público é gerado a partir das negociações discursivas entres os diferentes atores políticos. 0 processo de midiatização apresenta uma adequação dos políticos - e dos seus discursos - aos formatos da mídia (coletivas, transmissões ao vivo, comunicados em rádio etc.) tornando mediada um tipo de interação outrora face a face. A interação social é regida pela representação na medida em que os participantes adaptam a sua performance às expectativas de determinado momento/ situação. A personificação da política moderna e midiatizada do respeito ao modo como os políticos representam sua persona pública, o discurso do político foi sendo substituído, passando de uma oratória impecável a um diálogo coloquial, visando à conexão com o grande público. Fairclough (2008) identificou a incidência deste fenômeno ao tratar da "conversacionalização" da comunicação pública, que se traduz no uso da linguagem informal em todas as situações sociais, na tentativa de reprodução de um ethos igualitário. 0 discurso não é uma soma de sentenças, ele está sempre implicado em uma relação com os fenômenos sociais e suas condições de produção e reconhecimento.

A cidade e a imprecisão que talvez a defina - como polifonia ou mosaico - pode ser vista sob diferentes perspectivas. Por um lado, ela pode ser entendida como uma organização ou sistema vivo, se evocarmos parâmetros da Biologia (Lowie, 1970), ao passo que podemos percebê-la também a partir de sua identidade cultural, se transitarmos no campo da Gestão Social (Fischer, 1996). Sob outro ponto de vista, percebemos o quanto a cidade é discursiva se considerarmos a multiplicidade de vozes (Canevacci, 1993) que perfazem a antropologia urbana, o que requer uma abordagem interpretativa dos significados. Nesta ambiência de profusão de sentido, as cidades projetam-se enquanto marcas a partir de construtos de imagem produzidos para além dos aspectos culturais que conformam a sua identidade, constituindo-se em uma construção também de natureza discursiva. As estratégias utilizadas para esta atribuição de sentidos são as mais diversas, perpassando distintos atores sociais. No contexto aqui analisado, a administração pública, a partir do discurso político, detém um papel relevante no processo de construção da marca-lugar.

\section{MÉTODO}

Analisamos o discurso de posse do prefeito eleito de Salvador (BA) para o ciclo 2013 a 2016, buscando registrar os momentos em que a cidade foi citada, por meio da utilização de dois descritores para este recorte: "Salvador" e "Cidade". A escolha por estes descritores se deu pelo enfoque buscado nesta pesquisa, uma vez que a ideia de marca-lugar invariavelmente estará relacionada ao nome (Salvador) e à sua distinção espacial (a cidade). Ou seja, aspectos do discurso relacionados à campanha eleitoral, ataques a adversários políticos ou outros temas foram excluídos desta análise. Buscou-se, dessa forma, identificar que ideia de cidade estava presente discursivamente, de forma preliminar, em uma etapa que antecedeu o início da gestão. Havia uma visão de cidade - ou de intenções sobre a cidade - que seriam trabalhadas posteriormente, em conjunto com outras estratégias de comunicação desenvolvidas ao longo do tempo. A escolha desse ciclo de gestão em específico se deu por: 1) esta ter sido uma gestão que se utilizou fortemente de dispositivos de mídia, com a realização de campanhas audiovisuais e uso de redes sociais, reflexo da crescente midiatização da política nos dias atuais; 2) este período de gestão ter coincidido com o momento de investimento na concepção de marca para a cidade, considerando a realização de megaeventos no Brasil e em Salvador em datas próximas (Olímpiadas e Copa do Mundo)'; 3) ter sido reconhecida a importância que este grupo político atribui a questões de imagem.

É elemento central na proposta de análise de Charaudeau (1999) a compreensão do discurso em observância da realidade social - plano situacional em que o discurso é produzido - e da intencionalidade daqueles que protagonizam os atos de

1 Outros discursos do prefeito ACM Neto, como aqueles relacionados aos eventos esportivos citados, que tiveram Salvador como cidade sede (Olimpíadas e Copa do Mundo), poderiam ser observados em pesquisas futuras comparativamente em relação aos sentidos que o prefeito atribuía à cidade em sua posse, como evidência de validação processual da estratégia e visão de cidade enunciadas no início da sua gestão. 
linguagem. Os discursos políticos de posse dos prefeitos, neste sentido, enunciam uma estratégia para a cidade atrelada ao momento histórico em que se desenvolvem, diferenciando-se de abordagens metodológicas que focam de maneira unilateral na dimensão linguística. 0 "projeto de fala" ao qual se refere Charaudeau é composto por objetivos que norteiam o discurso e que, em nosso fenômeno, indicam uma percepção sobre a cidade. Esta análise desenvolve-se a partir das perspectivas de sua criação e dos seus efeitos de sentido. É possível correlacionarmos essa visão ao que propõe Verón (1980) quando infere sobre a existência de uma "gramática da produção" e de uma "gramática de reconhecimento". A seguir, um modelo deste processo de produção e reconhecimento trazido por Verón (1997) e adaptado ao contexto trabalhado neste artigo:

Figura 1: Relações entre produção e reconhecimento

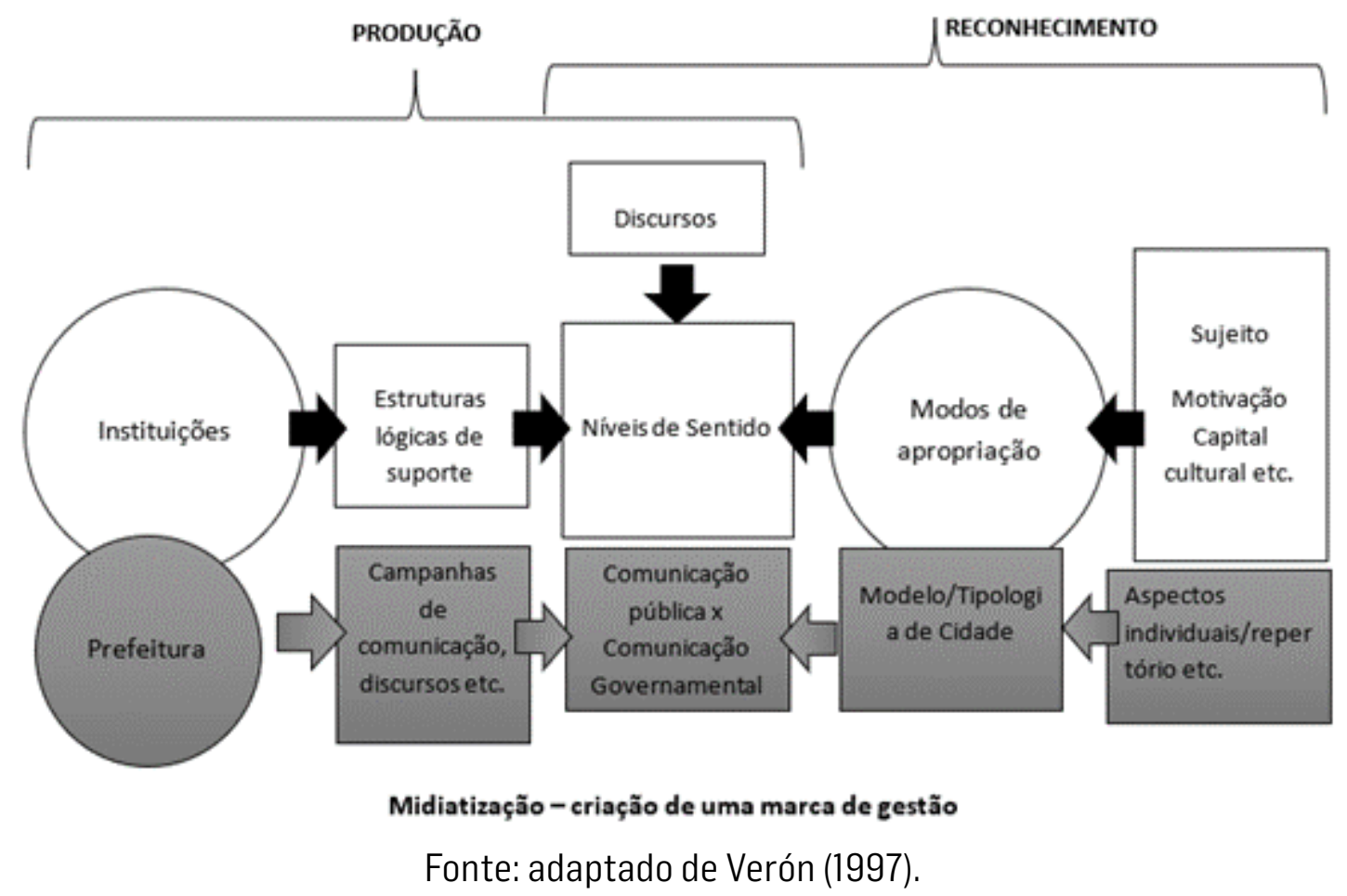

As categorias de análise trazidas neste artigo para investigação do discurso político posicionam a Prefeitura como instituição que, por meio de lógicas que lhes conferem suporte (campanhas de comunicação, comunicados oficiais), produzem discursos que operam e disseminam sentidos na esfera pública, perfazendo o espaço da comunicação pública. 0 reconhecimento desses discursos se dá pelos sujeitos (moradores da cidade, visitantes, turistas etc.), sendo apropriados por estes de diferentes formas, o que implica distintas visões de cidade possíveis. Retomando-se a perspectiva de Charaudeau (1999), há intenções estratégicas no discurso político que serão categorizadas de forma a evidenciar, a partir do projeto de fala do governante, a sua concepção de cidade.

\section{RESULTADOS}

Em seu discurso de posse, proferido em $2013^{2}$ na Praça Municipal, ACM Neto mencionou o termo "Salvador" em 24 oportunidades, enquanto o termo "cidade" apareceu em 27 ocasiões. Para além deste aspecto quantitativo, faz-se necessária uma percepção analítica de cunho qualitativo vinculada à ideia de marca-lugar proposta aqui.

2 Disponível em: https://www.correio24horas.com.br/noticia/nid/leia-o-discurso-de-posse-do-prefeito-acm-neto-empossado-nesta-terca-feira-10/. Acesso em: 25 ago. 2021. 
Quadro 1: Descritor 1-Salvador

\begin{tabular}{|c|c|}
\hline Menções a "Salvador" & Dimensão \\
\hline "Salvador não é um simples aglomerado urbano." & Imagem \\
\hline "Que ajudaram a tornar Salvador conhecida e admirada no mundo todo." & Imagem \\
\hline "Salvador é uma cidade viva, dinâmica e que não para de se transformar." & Transformação \\
\hline "[...] minha dedicação à nossa querida Salvador será total." & Gestão \\
\hline "Ninguém faz nada sozinho, muito menos administrar uma cidade do tamanho e da complexidade de Salvador." & Participação \\
\hline "Precisamos fazer um amplo pacto pela reconstrução de Salvador." & Participação \\
\hline "Podem ter certeza, em meu governo os interesses de Salvador vão estar sempre em primeiro lugar." & Gestão \\
\hline "Daqui a quatro anos quero que a saúde pública de Salvador seja vista com outros olhos por seus usuários." & Cidadão \\
\hline "Voltar a investir na instalação de novas unidades de saúde, como os Multicentros Salvador." & Gestão \\
\hline "que, daqui a quatro anos, Salvador seja uma cidade muito mais justa." & Igualdade de Direitos \\
\hline "Quero que a população de Salvador saiba que a partir de hoje tem um prefeito que vai chegar junto." & Gestão \\
\hline "Todos nós sabemos que Salvador passa hoje por uma grave crise financeira" & Economia \\
\hline "buscando novas parcerias onde a gente tiver de buscar e também exigindo aquilo que Salvador merece e tem direito." & Parcerias \\
\hline "Salvador será palco de grandes eventos esportivos." & Eventos \\
\hline "Vamos trabalhar para que Salvador seja orgulho de todos nós soteropolitanos." & Afetiva \\
\hline $\begin{array}{l}\text { "O turismo tem potencial para ser o motor da nossa economia. Salvador tem tudo pra } \\
\text { ser a capital da diversidade cultural e do turismo na América Latina." }\end{array}$ & $\begin{array}{l}\text { Diversidade } \\
\text { Cultura }\end{array}$ \\
\hline $\begin{array}{l}\text { "conversando com meu avô, ele me confessou que, como político, nunca se } \\
\text { sentiu tão realizado do que quando ele foi prefeito de Salvador." }\end{array}$ & Afetiva \\
\hline "ele colocou sua paixão a serviço de Salvador." & Afetiva \\
\hline "Tenho a convicção de que compartilhamos objetivos comuns para o bem de Salvador." & Parcerias \\
\hline "Sei que a maioria dos soteropolitanos compartilha comigo a fé de que Salvador irá cumprir o seu destino." & Participação \\
\hline Eu me atrevo a dizer que Salvador é a cidade do coração de muitos brasileiros." & Afetiva \\
\hline "Uma oportunidade para redescobrir a Salvador que tanto amamos." & Afetiva \\
\hline "Nasceu do diálogo com o povo de Salvador." & Participação \\
\hline "E quero oferecer os próximos quatro anos da minha vida a serviço de Salvador." & Gestão \\
\hline
\end{tabular}

Fonte: elaborado pelos autores.

É possível perceber uma intenção de busca de um maior envolvimento do cidadão (foco no cidadão; participação), ao passo que sinaliza a reafirmação de aspectos identitários (cultura, diversidade). Sob a perspectiva de uma marca, ela de fato necessariamente advém de uma identidade existente e que, no caso das cidades, emerge como um dos pontos fundamentais. Na fala do prefeito, é possível perceber que a identidade mantém uma relação direta com a dimensão do turismo e dos bens culturais, com possível impacto na economia local: "O turismo tem potencial para ser o motor da nossa economia". É uma visão pragmática para este campo, na qual os aspectos culturais parecem dialogar diretamente com a ideia de place branding, ou place tourism: "Salvador tem tudo pra ser a capital da diversidade cultural e do turismo na América Latina". Em outros momentos, o discurso oscila entre uma racionalidade subjetiva (afetiva) e uma ênfase a uma racionalidade administrativa (gestão; parcerias, transformação), culminando em um objetivo claro de fortalecimento da imagem da cidade, instância fim para a criação da ideia de uma marca-lugar. 
"enorme responsabilidade de resgatar o brilho e a alegria da nossa cidade."

"Uma cidade que nasceu para ser importante, para ter uma posição central no desenvolvimento do nosso país."

Imagem

"Uma cidade que, desde a sua fundação, foi cantada em verso e prosa, retratada das mais diversas formas. De Gregório de Matos a Jorge Amado, de Dorival Caymmi a Caetano Veloso, de Caribé a Pierre Verger, passando por Vinícius de Moraes, Raul Seixas, João Ubaldo, Antônio Risério, Mário Cravo, Daniela Mercury, Ivete Sangalo, Márcio Vitor, Pitty,

Cultura Mariela Santiago, Lucas Santana, Ronei Jorge, Fred Dantas, Letieris Leite, Sérgio Machado, e tantos, tantos."

"O soteropolitano tem muitos motivos para se orgulhar da sua cidade."

"O prefeito dessa cidade precisa saber respeitar essa história."

Psicológica

"Precisa compreender que essa cidade é um patrimônio."

História

"Salvador é uma cidade viva, dinâmica e que não para de se transformar."

Cultura

"Os problemas da cidade não serão resolvidos da noite para o dia."

Transformação

"Não vou deixar de tomar medidas duras, mas que são necessárias para tirar a nossa cidade da situação que ela se encontra."

Gestão

Gestão

"E para avançar de verdade, para colocar a nossa cidade de novo no eixo, vou precisar do apoio de todos vocês."

"Ninguém faz nada sozinho, muito menos administrar uma cidade do tamanho e da complexidade de Salvador."

Participação

"Não vou admitir que se negocie o futuro da nossa cidade em troca de favores e vantagens políticas."

Participação

"Muitas vezes, são problemas simples, mas que, somados, estão transformando a nossa cidade num verdadeiro caos."

"Não podemos nos esquecer também do dia de amanhã. É preciso planejar a nossa cidade, projetá-la para o século XXI."

Futuro

"Quero uma cidade que não traga tanto desconforto no trânsito, que tenha um transporte público

mais estruturado, com estações mais bem cuidadas, com ônibus novos e mais confortáveis."

"voltar a investir na instalação de novas unidades de saúde, como os Multicentros

Salvador, começando pelos bairros mais carentes da cidade."

Problemas

Futuro

"Daqui a quatro anos, queremos uma educação que seja exemplo para outras grandes cidades brasileiras."

Gestão

"Quero que, daqui a quatro anos, Salvador seja uma cidade muito mais justa."

"Infelizmente, a nossa cidade ainda é uma das capitais mais desiguais do país."

"A terceira maior cidade do país vai receber um tratamento digno de sua importância para a nação."

Gestão

"com as melhores práticas de governança, a nossa cidade vai conseguir captar muito mais investimentos."

"Eu vejo aqui uma excelente oportunidade para que a nossa cidade dê um salto no

seu desenvolvimento e cure de vez essa ferida na nossa autoestima."

"Eu quero que a alegria volte a tomar a conta da nossa cidade."

"A nossa cidade traz consigo quase 500 anos de história. Histórias de luta e superação."

"Eu me atrevo a dizer que Salvador é a cidade do coração de muitos brasileiros."

"Fazer tudo o que é possível, para devolver a essa cidade o brilho e o respeito que ela merece"

Educação

Igualdade de Direitos Igualdade de Direitos

História

Gestão

Psicológica

Afetiva

História

Afetiva

Afetiva

Fonte: elaborado pelos autores.

Há um elemento presente no discurso que se refere ao resgate de uma importância nacional de que Salvador, como primeira capital do país, já desfrutou: "[...] enorme responsabilidade de resgatar o brilho e a alegria da nossa cidade". De forma análoga, há reiteradas menções a aspectos culturais, patrimoniais e históricos, os quais se constituem como elementos distintivos que integram a noção de marca, por conferirem a identidade que será o elemento de diferenciação entre as localidades. 0 discurso tem um direcionamento para os cidadãos da cidade, ao mesmo tempo que projeta uma imagem para outros públicos, no sentido de posicionamento. Kapferer (1991) faz menção a atributos físicos e emocionais inerentes às marcas, sendo possível observar essa aplicação, respectivamente, nos trechos: "quero uma cidade que não traga tanto desconforto 
no trânsito, que tenha um transporte público mais estruturado" e "eu me atrevo a dizer que Salvador é a cidade do coração de muitos brasileiros".

Se compilarmos ambos os descritores - "Salvador" e "Cidade" -, visualizados anteriormente de forma isolada, pode-se perceber uma estratégia de posicionamento discursivo que perfaz o composto da marca-lugar naquele momento inicial de gestão:

Figura 2: Composto da marca-lugar

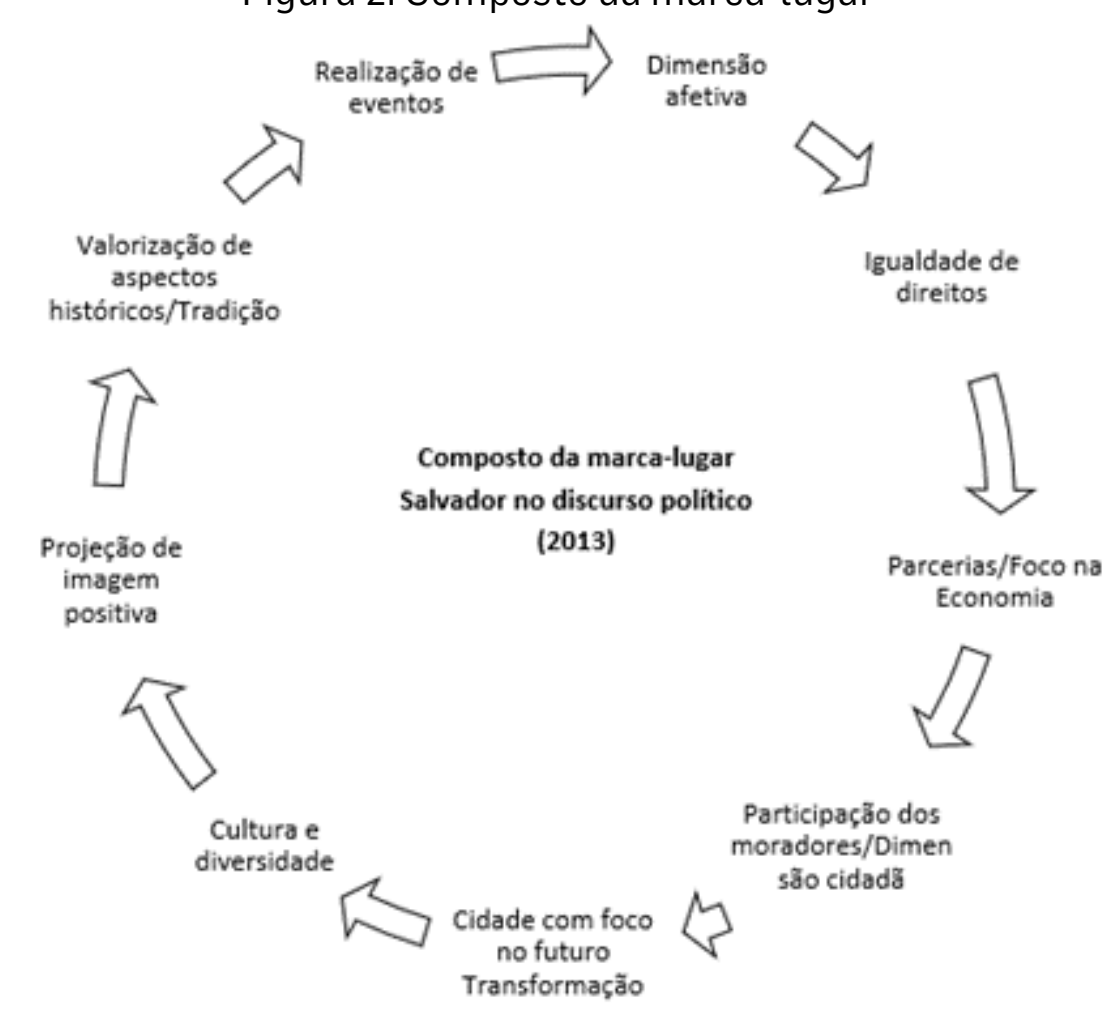

Os elementos presentes no discurso de posse do prefeito ACM Neto indicavam um direcionamento estratégico à época. 0 fenômeno de reinvenção das cidades sob a perspectiva das marcas e da comunicação evidencia a existência de um mercado simbólico das cidades, concorrencial e competitivo, em que a mídia, o Estado e as organizações têm papeis distintos e complementares. 0 discurso de posse dos prefeitos é entendido aqui como um momento inicial que indica sob quais parâmetros o contrato de comunicação de cada gestão estaria sendo elaborado. Que visão de cidade estava em jogo?

Há um ato de venda, tal qual em uma comunicação mercadológica, mas com um viés implícito: de uma visão/concepção de cidade. De todo modo, é certo que o discurso evidencia uma performance esperada de gestão. A rigor, esse desnível entre 0 discurso e o que se efetivará posteriormente pode levar, hipoteticamente, a uma quebra de contrato entre emissor e receptor. A administração pública move a sua comunicação enquanto "comunicação pública" para assegurar a performance de sua marca, de seu modelo de cidade. 0 cidadão pode não se reconhecer, nem a sua cidade e nem a si mesmo como beneficiário das ações.

0 discurso político trazido neste artigo pode nos conduzir a interpretações decorrentes, em última análise, de gramáticas que são distintas, nas quais as intenções entre produção e recepção não se efetivam de modo linear. No campo da comunicação pública, a princípio regida por variáveis tais como o interesse público, a informação, a escuta, dentre outras, há, de forma concomitante no discurso apresentado, uma intencionalidade de cunho publicitário, reflexo do contexto de midiatização contemporâneo em que vivemos. 


\section{CONSIDERAÇÕES FINAIS}

Neste artigo, buscamos problematizar a relação entre o discurso político e os aspectos simbólicos que integram a ideia de marca-lugar. Entendemos que há um ineditismo decorrente da correlação analítica entre a comunicação pública empreendida por entes governamentais e as noções de marca-lugar, uma vez que esta imagem que se projeta da cidade é construída a partir dos discursos dos governantes, das suas intervenções no espaço público e das estratégias e planos que ultrapassam uma primeira visão meramente turística, mas que perpassam as políticas públicas voltadas a outras áreas, como educação, mobilidade, infraestrutura e saúde. A cidade projetada é um somatório dessas perspectivas que inicialmente se expressa na fala dos governantes.

No que se refere ao método de análise empregado, é possível depreendermos a intencionalidade discursiva presente na análise de discurso de Charaudeau $(1999,2006 b)$ e de gramáticas de produção e reconhecimento (Verón, 1997), que findam por estabelecer um contrato de comunicação entre os cidadãos e a administração pública. Ao considerarmos o discurso político como parte integrante da compreensão sobre a marca-lugar, nos distanciamos de uma compreensão da marca ao final de uma cadeia simbólica - a marca criada unicamente com a finalidade de circulação em campanhas - para um momento inicial e de concepção mais subjetivo, que implicitamente está presente no "projeto de fala" do gestor público.

Por fim, reforça-se o aspecto de que a cidade se consolida como uma organização discursiva, sendo passível a análise das múltiplas vozes que a compõem. Propõe-se a realização de um estudo comparado dos discursos de posse dos prefeitos de Salvador, uma vez que este demonstra o momento inicial em que se evidencia uma perspectiva de criação de uma marcalugar da cidade, contemplando diferentes ciclos de gestão. Há uma manutenção destas visões de cidade ao longo dos ciclos de gestão? Que aspectos são convergentes ou divergentes ao longo dos anos? Este é um recorte inicial de um período, mas entendemos que pode ser correlacionado com o discurso de outros prefeitos de uma mesma cidade ao longo dos anos e, com isso, podemos obter uma visão consolidada temporalmente, a qual imprime à cidade uma marca que lhe é distintiva.

\section{REFERÊNCIAS}

CANEVACCI, Massimo. A Cidade Polifônica: ensaio sobre a antropologia da comunicação urbana. Tradução de Cecília Prada. São Paulo: Studio Nobel, 1993.

CHARAUDEAU, Patrick. A conquista da opinião pública: como o discurso manipula as escolhas políticas. São Paulo:Contexto, 2016.

CHARAUDEAU, Patrick. Análise do discurso: controvérsias e perspectivas. In: MARI, Hugo; PIRES, Sueli; CRUZ, Amadeu Roselli; MACHADO, Ida Lúcia (org.). Fundamentos e dimensões da análise do discurso. Belo Horizonte: Carol Borges, 1999. p.27-43.

CHARAUDEAU, Patrick. Discurso das mídias. São Paulo: Contexto 2006b.

CHARAUDEAU, Patrick. Discurso político. São Paulo: Contexto, 2006a.

FAIRCLOUGH, Norman. Discurso e mudança social. Brasília, DF: Editora da UnB, 2008.

FISCHER, Tânia. Gestão contemporânea, cidades estratégicas: aprendendo com fragmentos e configurações do local. $/ m$ : FISCHER, Tânia. Gestão Contemporânea: cidades estratégicas e organizações locais. Rio de Janeiro: Editora da FGV, 1996. p.13-23. 
HJARVARD, Stig. The mediatization of society: a theory of the media as agents of social and cultural change. Nordicom Review, Göteborg, v.29, n.2, p.105-134, 2008.

KAPFERER, Jean-Noel. As marcas, capital da empresa-criar e desenvolver marcas fortes. São Paulo: Bookman, 1991.

KAVARATZIS, Mihalis; ASHWORTH, Gregory John. City branding: an effective assertion of identity or a transitory marketing trick? Place Brand Public Diplomacy, n.2, p.183-194, 2006.

LOWIE, Robert H. Organização social. In: PIERSON, Donald (org.) Estudos de organização social. São Paulo: Martins, 1970. v.2, p.139-155.

LYNCH, Kevin. The image of the city. Cambridge: The MIT Press, 1960.

SANTOS, Milton. A natureza do espaço: técnica e tempo, razão e emoção. São Paulo: Hucitec, 1996.

SEMPRINI, Andrea. A marca pós-moderna. São Paulo: Estação da Letras, 2006.

SIMÕES, Roberto Porto. Relações Públicas e micropolítica. São Paulo: Summus, 2001.

SIMÕES, Roberto Porto. Relações Públicas: função política. 3.ed. São Paulo: Summus, 1995.

SODRÉ, Muniz. Antropológica do espelho: uma teoria da comunicação linear e em rede. Petrópolis: Vozes, 2002.

STRÖMBÄCK, Jesper; KIOUSIS, Spiro. Political public relations: principles and applications. New York: Taylor \& Francis, 2011.

VERÓN, Eliseo. A produção de sentido. São Paulo: Cultrix, 1980.

VERÓN, Eliseo. Esquema para el análisis de la mediatización. Diálogos de la Comunicación, Lima, n.48, p.9-17, 1997.

Artigo recebido em 30.04.2021 e aprovado em 09.08.2021. 